\title{
A PROFISSÃO DOCENTE NAS REPRESENTAÇÕES SOCIAIS DE PROFESSORES INICIANTES DE ENSINO MÉDIO'
}

\author{
Laêda Bezerra Machado² \\ Mayara Corrêa da Silva ${ }^{3}$
}

\section{RESUMO}

Este artigo identifica as representações sociais do ser professor construídas por docentes de ensino médio em início de carreira. Adotamos como referencial a abordagem societal das representações sociais. O texto resulta de uma pesquisa qualitativa, que envolveu 15 professores de instituições públicas de Recife-PE. Utilizamos como instrumento de coleta de dados a entrevista semiestruturada. $O$ material recolhido foi analisado com o auxilio do software Alceste. As representações do ser professor dos docentes de ensino médio ressaltam a importância do serviço prestado por esse profissional à sociedade. Os depoimentos, organizados em classes, sugerem representações sociais centradas na capacidade de mediação do conhecimento e possibilidade de transformação social. Contudo, tais representações estão marcadas pelo sentimento de desvalorização. Os iniciantes na docência reiteram que diferentes elementos de precarização afetam o ser professor hoje, tais como baixo prestígio social da profissão, má remuneração, exigências constantes por parte dos sistemas, indisciplina e desinteresse dos alunos. Além de detectar o cenário de desvalorização do docente de ensino médio e suas influências para as práticas dos professores iniciantes, sugerimos a implementação de políticas públicas, que acolham e ofereçam maior suporte ao professor de ensino médio em início de carreira que atua na escola pública.

Palavras-chave: Professor. Ensino médio. Representações sociais. Iniciante.

\section{THE TEACHING PROFESSION IN THE SOCIAL REPRESENTATIONS OF TEACHERS INITIATIVES OF MIDDLE SCHOOL}

\begin{abstract}
This article identifies the social representations of being a teacher built by high school teachers early in their careers. We adopt as reference the societal approach of

1 O artigo decorre de uma pesquisa mais abrangente, financiada pelo CNPq, desenvolvida no período de 2014-2017.

2 Doutora em educação. Professora vinculada ao Departamento de Administração Escolar e Planejamento Educacional da Universidade Federal de Pernambuco. Recife-PE - Brasil. Bolsista de Produtividade em Pesquisa CNPq. ORCID ID: https://orcid.org/0000-0002-9524-03. E-mail: laeda01@gmail.com

3 Graduação em Pedagogia pela Universidade Federal de Pernambuco. Universidade Federal de Pernambuco Recife-PE - Brasil. ORCID ID: https://orcid.org/0000-0002-7219-5041. E-mail: mayara.correa30@gmail.com
\end{abstract}


social representations. The text results from a qualitative research that involved 15 professors from public institutions of Recife-PE. We use as a data collection instrument the semi-structured interview. The material collected was analyzed with the help of Alceste software. The representations of being a teacher of high school teachers emphasize the importance of the service provided by this professional to society. The statements, organized into classes, suggest social representations centered on the capacity to mediate knowledge and the possibility of social transformation. However, such representations are marked by the feeling of devaluation. The beginners in teaching reiterate that different elements of precariousness affect the being teacher today, such as low social prestige of the profession, bad remuneration, constant demands by the systems, indiscipline and disinterest of the students. In addition to detecting the scenario of the devaluation of high school teachers and their influences on the practices of beginning teachers, we suggest the implementation of public policies that welcome and offer greater support to the high school teacher at the beginning of the career that works in the public school.

Keywords: Teacher. High school. Social representations. Beginner.

\section{LA PROFESIÓN DOCENTE EN LAS REPRESENTACIONES SOCIALES DE INICIATIVAS DE PROFESORES DE LA ESCUELA INTERMEDIA}

\section{RESUMEN}

Este artículo identifica las representaciones sociales del ser profesor construidas por docentes de enseñanza media en inicio de carrera. Adoptamos como referencial el abordaje societal de las representaciones sociales. El texto resulta de una investigación cualitativa que involucró a 15 profesores de instituciones públicas de Recife-PE. Utilizamos como instrumento de recolección de datos la entrevista semiestructurada. El material recogido fue analizado con el auxilio del software Alceste. Las representaciones del ser profesor de los docentes de enseñanza media resaltan la importancia del servicio prestado por ese profesional a la sociedad. Los testimonios, organizados en clases, sugieren representaciones sociales centradas en la capacidad de mediación del conocimiento y posibilidad de transformación social. Sin embargo, estas representaciones están marcadas por el sentimiento de devaluación. Los iniciantes en la docencia reiteran que diferentes elementos de precarización afectan al ser profesor hoy; tales como bajo prestigio social de la profesión, mala remuneración, exigencias constantes por parte de los sistemas, indisciplina y desinterés de los alumnos. Además de detectar el escenario de desvalorización del docente de enseñanza media y sus influencias para las prácticas de los profesores principiantes, sugerimos la implementación de políticas públicas, que acojan y ofrezcan mayor soporte al profesor de enseñanza media en inicio de carrera que actúa en la escuela pública.

Palabras clave: Profesor. Enseñanza media. Representaciones sociales. Principiante.

\section{INTRODUÇÃO}

Já algum tempo, estamos a coordenar e orientar pesquisas com professores utilizando o referencial das representações sociais. Nesse 
percurso, temos percebido que vários são os desafios enfrentados por docentes em início de carreira. Temos detectado que os professores iniciantes na profissão são aqueles que apresentam posicionamentos mais negativos para com a docência, os que consideram os conteúdos dos cursos de formação muito teóricos e distanciados da realidade das escolas e até minimizam a contribuição desses cursos para o desempenho de suas atividades docentes.

Em estudo que desenvolvemos sobre as representações sociais e práticas de bons professores nos ciclos de aprendizagem (MACHADO; RAPOSO; CASTRO, 2015), não localizamos professores com esse perfil (reconhecidos como bons) que estivessem em início da carreira. Em geral, os professores considerados de sucesso são os que já superaram o choque de realidade próprio do início da docência. Conforme Garcia (1999, p. 28), choque de realidade refere-se ao "período de confrontação inicial do professor com as complexidades da profissão e as condições de permanência deste profissional na docência, apesar de todas as agruras que vivencia".

Huberman (1995) discute os diferentes estágios da carreira e caracteriza como inicial o período do ingresso até os três anos de profissão. A fase inicial diz respeito a um período de sobrevivência e descoberta. A sobrevivência tem a ver, de acordo com autor, com o "choque de realidade", decorrente dos primeiros embates com a complexidade e imprevisibilidade, que caracterizam a sala de aula. O professor iniciante para "sobreviver" precisa superar os seguintes desafios: descompasso entre os ideais educacionais e a vida cotidiana nas salas de aula e nas escolas; fragmentação do trabalho; dificuldade em combinar ensino e gestão de sala de aula; falta de materiais didáticos; e dificuldades de relacionamento. O elemento de descoberta é inerente ao entusiasmo do iniciante, com o orgulho de ter sua própria classe e fazer parte de um corpo profissional. As características de sobrevivência e descoberta caminham lado a lado, no período de entrada na carreira, período marcado por crises e dificuldades para os docentes (HUBERMAN, 1995). 
A fase inicial da docência, segundo Tardif (2002, p. 84), constitui "[...] um período muito importante da história profissional do professor, determinando inclusive seu futuro e sua relação com o trabalho".

Garcia (1999, p. 113) considera o estágio inicial da carreira como "um período de tensões e aprendizagens intensivas em contextos geralmente desconhecidos nos quais os professores principiantes devem adquirir conhecimento profissional, além de conseguirem manter certo equilíbrio pessoal". A inserção na carreira docente, como salientam Lima et al. (2006), é, portanto, um momento peculiar, marcado por inúmeras descobertas e conflitos.

Este artigo procura identificar as representações sociais do ser professor construídas por docentes de ensino médio em início de carreira. O interesse pelo ensino médio relaciona-se à sua própria finalidade e desafios, além disso vincula-se à escolha da abordagem societal das representações sociais, que valoriza a inserção do sujeito em diferentes grupos de pertencimento. A investigação abrange diferentes docentes que atuam nas três etapas da educação básica, tendo sido o enfoque deste artigo os docentes iniciantes de ensino médio.

Lembramos que a última etapa da educação básica foi sempre objeto de discussão em nosso país, porque ora profissionaliza, ora assume função propedêutica. A dicotomia (profissionalizar ou dar prosseguimento aos estudos na educação superior) atravessa a história desse ensino. Conforme Krawczyk e Ferratti (2017), o ensino médio tem sido alvo de preocupações por parte de gestores, professores, pesquisadores e entidades educacionais.

Em 2017, foi aprovada uma reforma ${ }^{4}$ para essa etapa da educação, com vários pontos controversos. Para Coradini (2017), os principais giram em torno das condições necessárias para a efetivação do "novo ensino médio", como infraestrutura, equipamentos e professores qualificados. Essas condições se tornam quase impossíveis diante do quadro de redução do

\footnotetext{
${ }_{4}^{4}$ Lei $n^{\circ}$ 13.415. Altera as Leis nos 9.394, de 20 de dezembro de 1996, que estabelece as diretrizes e bases da educação nacional, e 11.494, de 20 de junho 2007.
} 
financiamento da educação e com a valorização do critério "notório saber" para contratação de professores, ou seja, a contratação de professores sem formação própria para assumir a função docente. Na visão do autor, a reforma ameaça a qualidade do ensino médio, pois ela define propostas líquidas, de caráter instrumental da formação dos adolescentes e jovens no Brasil.

Sobre a produção acadêmica acerca do professor iniciante no Brasil, ela tem crescido e, dentre as análises dessa produção, destacam-se as elaboradas por Papi e Martins (2009), Corrêa e Portella (2012), Papi e Carvalho (2013), Cunha, Voltarelli e Costa (2013) e Machado (2017). Nestes trabalhos, os autores reconhecem que a quantidade de estudos sobre 0 professor em início de carreira aumentou. No entanto, ressaltam que há uma concentração de estudos com docentes dos anos iniciais do ensino fundamental e educação superior. Por conseguinte, reiteram a necessidade de novos investimentos em pesquisas sobre o início da carreira.

Para a pesquisa que deu origem a este artigo, realizamos um levantamento bibliográfico a fim de atualizar o debate científico sobre o professor iniciante. Analisamos os resumos de teses e de dissertações sobre o tema contidos no banco da CAPES, tomando como referência o período que compreende os anos de 2013 a 2016. Os trabalhos selecionados importaram em um total de 54 produções, distribuídos em 43 dissertações e 11 teses. A maioria das produções (45 trabalhos) foi desenvolvida em programas de pós-graduação em educação5. A revisão dessa literatura possibilitou uma aproximação mais segura com a discussão sobre o professor iniciante no país e reforçou que o processo de inserção na carreira docente constitui-se como uma etapa profissional peculiar. Nessa fase, há incertezas e inseguranças geradas em relação à teoria e à prática, bem como inúmeras descobertas que repercutem na prática profissional.

As pesquisas analisadas revelam uma variedade de lacunas decorrentes da formação inicial do docente, que implicam em dificuldades

5 Os demais trabalhos foram desenvolvidos em cursos de pós-graduação em História, Geografia, Letras, Linguística e Desenvolvimento Humano. 
a serem enfrentadas no início da carreira. Como reiteram os trabalhos, a entrada na carreira, geralmente, é um momento de expectativas, marcado por sentimentos de insegurança, incertezas e medos, além da principal dificuldade desse período inicial, que diz respeito à organização da prática pedagógica. Nos resultados dessas pesquisas, tais dificuldades e dilemas são associados às lacunas da formação inicial.

No ambito metodológico, a abordagem qualitativa é predominante nos estudos sobre e com o professor iniciante. Os sujeitos participantes dos estudos são professores, que atuam em diferentes níveis e modalidades de educação e ensino e possuem com até cinco anos de exercício na docência. Contudo, prevalece na produção científica os trabalhos com docentes dos anos iniciais do ensino fundamental e educação superior. No conjunto da produção analisada, não localizamos trabalhos que abordassem professores iniciantes que atuam no ensino médio. Também, não identificamos pesquisas subsidiadas pela Teoria das Representações Sociais. Assim, considerando que a entrada na carreira docente potencializa conflitos, além dos desafios comuns à organização e funcionamento do ensino médio, enfocamos, neste artigo, as representações sociais da profissão docente construídas por profesores iniciantes que atuam nessa etapa da educação básica.

\section{REFERENCIAL TEÓRICO}

Em termos etimológicos, na Europa e, em particular, na França, a palavra profissão está associada a "professio", do latim "profiteri", que significa confessar, testemunhar, declarar abertamente. Dessa palavra, provém, por exemplo, a expressão "profissões de fé". Em sua gênese, o reconhecimento de uma "profissão" se dá a partir do saber professado e reconhecido em público, um saber que possui conotação diferenciada quando comparado à noção de métier, originada de do termo ministérium, que quer dizer "estar ao serviço de". 
Nos dicionários brasileirosb, as palavras "profissão" e "ofício" são indicadas como sinônimas. Particularmente, a aplicação do termo "ocupação" parece, à primeira vista, se aproximar do significado do "[...] conjunto de pessoas exercendo um mesmo métier [...]", como indica Dubar (2005, p. 167), referindo-se ao contexto francês, significação semelhante à verificada na Classificação Brasileira de Ocupações (CBO)7.

Conforme situa Weber (2003), as profissões podem ser abordadas por diferentes enfoques e cita Freidson (1998) como um autor que considera "conhecimento e competências especializadas" como elementos caracterizadores de uma profissão. Weber (2003, p. 1127) refere-se à profissionalização:

[...] como processo que transforma uma ocupação no mundo do trabalho mediante a circunscrição de um domínio de conhecimentos e competências específicos, como processo que, calcado nas características de profissões estabelecidas (as profissões liberais), nomeia, classifica uma ocupação como profissão, associando-lhe imagens, representações, expectativas historicamente definidas, ou como processo de reconhecimento social de uma atividade ou ocupação, tem sido objeto de debate frequente no âmbito da produção sociológica que pretende esclarecer os elementos centrais das sociedades contemporâneas.

Ludke e Boing (2004) citam Bourdoncle (1991 e 1993)', para quem uma profissão não é algo fácil de se definir, contudo destacam um atributo comum a todas elas, isto é, uma especialização, um saber próprio, peculiar. Bourdoncle (1991 apud Lüdke e Boing, 2004) destaca quatro critérios comuns a todas as profissões: uma base de conhecimentos sistematizados; interesse coletivo acima dos pessoais; código de ética controlado pelos pares; e honorários pagos pelos serviços prestados.

6 LAROUSE. Dicionário da língua portuguesa. São Paulo: Ática, 2002.

HOUAISS, A. Dicionário da língua portuguesa. Rio de Janeiro: Objetiva, 2007.

FERREIRA, A. B.H. Dicionário da língua portuguesa. 4a . Ed. Rio de Janeiro, 2002.

${ }^{7}$ Ministério do Trabalho e Emprego do Brasil. www.mte.gov.br

8 BOURDONCLE, R. La professionnalisation des enseignants: analyses sociologiques anglaises et américaines. Revue Française de Pédagogie, Paris, n. 94, jan./mar. 1991.

BOURDONCLE, R. La professionnalisation des enseignants: les limites d'un mythe. Revue Française de Pédagogie, Paris, n. 105, 1993. p. 83-119. 
Sem ignorar o complexo debate em torno do que seja profissão, Enguita (1998) demarca critérios comuns aos grupos profissionais. Os critérios demarcados pelo autor são competência profissional, vocação, licença e autorregulação. A competência refere-se a um corpo de conhecimentos, destrezas e habilidades resultantes de formação específica e de longo tempo. No contexto brasileiro, poderíamos chamar de formação inicial e, semelhante ao que sugere Bourdoncle (1991), vocação seria o que chama de um interesse geral. A licença é constituída pelos modos de recrutamento para um campo próprio ou exclusivo de atuação, que é reconhecido e protegido pelo Estado; a independência relaciona-se à autonomia no exercício profissional frente à organização e aos clientes e, por fim, a autorregulação diz respeito a um código de ética, a uma entidade ou a uma associação organizada para resolução de conflitos.

No que tange à profissão docente, Nóvoa (1991) assinala que, no processo histórico de seu desenvolvimento, vão surgindo reivindicações socioprofissionais, tais como o reconhecimento do caráter especializado da ação educativa e de sua relevância social.

Segundo Roldão (2007), o que demarca a profissão de professor é a ação de ensinar. A autora afirma que, ao longo da história, o ensino existiu sob muitos formatos e com diversos estatutos, tendo assumido diferentes conotações conceituais entre a postura tradicional do "transmitir um saber" e a leitura mais pedagógica do "fazer aprender alguma coisa a alguém". Atualmente, o ensino é caracterizado pela figura da dupla transitividade e pelo lugar de mediação, atrelado ao sentido do segundo conceito da especialidade de fazer alguém aprender alguma coisa.

Ensinar, conforme Tardif e Lessard (2005, p. 31), significa "[...] trabalhar com humanos, sobre seres humanos e para seres humanos". Para os autores, a ênfase no trabalho com o humano ganha centralidade na profissão docente.

A docência, como profissão, foi se tornando complexa ao longo do tempo, indo além da função de ensinar, pois passou a exigir novas condições de trabalho. Nóvoa (1995) define tais mudanças como parte do 
processo de profissionalização, que corresponde à tomada de consciência do corpo docente e de seus interesses como grupo profissional. Ao processo de profissionalização, vinculam-se duas dimensões: a definição de um corpo de conhecimentos e de técnicas e a elaboração de um conjunto de normas e valores.

De acordo com Weber (2003), no Brasil, como em outros países, a profissão docente foi sendo normatizada a partir do período em que o Estado tomou para si o controle da escola, com a finalidade de atender às necessidades de escolarização impostas pelo processo de modernização da sociedade. A autora, utilizando-se de um referencial da Sociologia das Profissões, retraça a trajetória da profissão docente no país, e mostra o papel do Estado, das instituições formadoras de professores e das associações ou entidades profissionais em tal percurso. Ao referir-se ao Estado, apresenta seu papel regulador e normativo através da evolução da legislação educacional, suas implicações e repercussões para docência; e, em relação às instituições formadoras, evidencia seus projetos formativos. Além disso, ressalta o papel das entidades, suas lutas, embates e reivindicações para com a docência. Podemos inferir que as três instâncias citadas por Weber (2003) têm sido responsáveis por produzir e reproduzir um corpo de saberes e um sistema de normas próprias, que caracterizam a profissão docente no país.

No entanto, o que apresentamos, a respeito de critérios, que caracterizam a profissão docente no Brasil, ou seja, o discurso oficial em favor da profissionalização docente, conforme Hypólito (1999), não tem surtido efeitos práticos. Na sua visão, esse discurso assume uma função disciplinadora, controladora e ideológica, pois as condições concretas, sobre as quais a atividade docente se realiza, são cada vez mais desqualificadas. Os professores são submetidos, dentre outros aspectos, ao rebaixamento de salários e à diminuição das chances de acesso aos bens culturais, portanto, contrariam o que se denomina como profissionalização da docência. 
Em consonância com Hipólito (1999), Dourado (2001) reconhece a formação inicial insuficiente, os baixos salários e as precárias condições de trabalho como elementos que sinalizam para uma aguda proletarização docente. Na mesma linha de argumentação, Lüdke e Boing (2004) afirmam que não se pode desconsiderar que o professor vivencia, hoje, sinais evidentes de precarização em termos de valorização, prestígio, poder aquisitivo, condições de vida, respeito e satisfação no exercício do magistério. Tal cenário põe em risco a profissionalização.

Alves e André (2013), em um estudo sobre profissionalidade, ressaltam a crise do ofício de professor como resultado da confluência de vários fatores, tais como: baixos salários, minguadas condições de trabalho, pressão das avaliações institucionais externas e poucas horas de estudo. Os autores acrescentam que a precarização da docência concorre para afastar, cada vez mais, os jovens da carreira docente, que não lhes oferece atrativos?.

Em geral, as profissões resultam de uma dinâmica social, pois estão em constantes transformações e procuram sempre atender as demandas da sociedade. Uma profissão é um tipo específico de trabalho, que vai variar de acordo com as habilidades e os conhecimentos, que são necessários para exercê-la.

Em revisão da literatura sobre a profissão docente no Brasil, Cericato (2016) afirma que, de modo geral, as profissões resultam de uma dinâmica social, porque estão em constante busca para atender as demandas da sociedade. Para se caracterizar uma profissão, são necessárias competências especializadas e formais, adquiridas através de formação técnica. Conforme a autora, por meio de uma profissão, interliga-se um conjunto de saberes e de pessoas, estabelecendo as exigências, que buscam demarcar os parâmetros para uma determinada atividade. Lembra, ainda, que dentre esses saberes, se destacam o conhecimento

\footnotetext{
9 TARTUCE, G. L. B. P.; NUNES, M. M. R e ALMEIDA, P. C. A. de. Atratividade da carreira docente no Brasil: Relatório Preliminar. São Paulo: Fundação Carlos Chagas, outubro de 2009.
} 
especializado, a aquisição de técnicas, o grau de autonomia e a organização, o que confirma a competência e fixa as regras da atividade profissional.

Ainda, segundo Cericato (2016), na literatura há certa dificuldade para se definir a docência como uma profissão, em decorrência de alguns fatores, por exemplo, a estatização, que retira a autonomia do professor, uma vez que o Estado regulamenta, licencia e fiscaliza. Além disso, não há qualquer regulamentação interna para a profissão docente. Por exemplo, os arquitetos, médicos, contadores possuem conselhos próprios para uma maior fiscalização e defesa de seus respectivos campos/territórios de ação. Tais conselhos procuram normatizar o campo de ação de cada profissão, o que se traduz em segurança profissional e maior autonomia. Como diz a autora, a profissão docente assim como as demais profissões, enfrenta seus desafios, dentre os quais merecem destaques: desvalorização social, precariedade das condições de exercício profissional, fragilidade da formação técnica e baixos salários. No entanto, definimos a docência como profissão, pois assim como as outras profissões, tem o seu conhecimento específico, resultado de uma formação especializada. Não é qualquer indivíduo que está apto a exercer a docência, porque não basta, apenas, dominar os conteúdos de ensino. Trata-se de uma profissão, em que se estabelece uma relação com o objeto do trabalho: o sujeito (ser humano) que aprende.

As considerações em torno da profissão docente revelam a situação de crise e precarização vivenciada pelos professores, fenômenos que podem, de algum modo, justificar a tendência à evasão do magistério na fase inicial da docência, já revelada por outros autores internacionais e nacionais. Considerando o cenário apresentado e discutido, relativo à profissão, estamos cientes de que os professores em início de carreira constroem representações sociais da "profissão docente". Assim, procuramos neste artigo identificá-las, indicando seus elementos comuns e variações entre docentes que atuam no ensino médio. 
A Teoria das Representações Sociais vem se disseminando em várias partes do mundo, tem sido tomada como referência para estudo dos mais diferentes fenômenos e estabelece diálogos com diversas teorias. Da interlocução com outros referenciais, surgem outras vertentes, que aprofundam as ideias, os conceitos e os pressupostos originais de Moscovici, ou seja, florescem novos desdobramentos da grande teoria. Sá (1998)10 destaca três correntes, a saber: a original ou cultural, a abordagem estrutural e a societal. Provenientes de uma mesma matriz, tais correntes convivem pacificamente, sem que uma desautorize a outra, pois possuem pontos de articulação, convergência e alguns desacordos.

Doise (2002), inspirado em Serge Moscovici, apresenta um quadro teórico complexo e estimulante, que articula o estudo de sistemas cognitivos no nível do indivíduo ao estudo dos sistemas relacionais e societais. Apoia-se em Henri Tajfel (1919-1982), que realizou diversas pesquisas fazendo intervir a comparação intergrupo como o motor da construção de uma identidade social positiva e, também, em Jean Piaget (1896-1980), que, através de uma análise sociocognitivista, considera a intervenção do social como fundamento para o desenvolvimento moral dos indivíduos. Esses dois teóricos foram os principais mestres de W. Doise, com os quais estabeleceu diálogos epistemológicos para a construção da abordagem societal no estudo das representações sociais.

A abordagem societal procura articular o individual ao coletivo, busca interligar explicações de ordem individual com explicações de ordem societal e, sobretudo, explicita que os mecanismos e processos usados pelos indivíduos para viver em sociedade são orientados por dinâmicas interacionais, valores e crenças. Nessa abordagem, as representações sociais são princípios geradores de tomadas de posição e tais princípios estão direta e simbolicamente vinculados à posição ocupada pelo sujeito no grupo (DOISE, 2002).

\footnotetext{
$10 \mathrm{Na}$ atualidade, podemos nos referir a quarta vertente, a epistemologia dialógica das representações sociais, que valoriza os processos linguísticos e tem como principal protagonista Yvana Marková.
} 
De acordo com Doise (2001, p. 193), "[...] a Psicologia Social quase não construiu conceitos que permitam articular os funcionamentos cognitivos individuais com as dinâmicas sociais mais amplas, das quais participam os indivíduos". E esta parece ser a questão que motivou particularmente suas investigações na tentativa de superação dos limites da Psicologia Social, relativas à dicotomia indivíduo e sociedade e, também, às análises sobre dissensos e consensos, que estão presentes no indivíduo e nos grupos de pertença.

A abordagem societal considera que, nas representações sociais de um objeto, há sempre uma partilha de crenças comuns entre os diferentes membros de um grupo e, também, diversificações, porque os indivíduos se diferenciam entre si nas relações que mantêm com esses objetos de representação. O foco das pesquisas que adotam essa abordagem tem sido a análise do entendimento comum (consensos) e a organização das tomadas de posição individuais (variações). Considerando a perspectiva dos grupos, neste artigo, procuramos, justamente, indicar os consensos e variações das representações sociais da profissão docente entre um grupo de professores de ensino médio.

\section{PROCEDIMENTOS METODOLÓGICOS}

Estudos fundamentados na Teoria das Representações Sociais, em geral, adotam a abordagem qualitativa, uma vez que tal vertente lida melhor com os significados atribuídos a objetos diversos pelos sujeitos. Conforme considerações de Minayo (2016), a abordagem qualitativa procura desvelar processos sociais pouco conhecidos e que pertencem a grupos particulares, sendo seu objetivo proporcionar a construção de conceitos e categorias referentes ao fenômeno estudado.

Desenvolvemos a investigação com 15 professores iniciantes de ensino médio, que atuam em escolas públicas de Recife-PE. Os critérios para seleção dos participantes foram, assim, definidos: possuir formação em licenciatura e atuar a até três anos como docente de ensino médio. O grupo participante foi constituído de 11 mulheres e 4 homens e todos atuam em 
escolas da rede estadual de ensino. Dos professores entrevistados, sete são graduados em Letras, três em Química, dois em Matemática, um em Geografia, um em História e outro em Física. Desses docentes, treze possuem curso de especialização. Sobre o tempo de experiência docente, oito professores estão com até três anos; quatro com até dois anos de docência e três estão com até um ano de exercício profissional. As idades dos docentes variaram de 27 a 33 anos.

O instrumento utilizado para recolha dos dados foi uma entrevista semiestruturada. Entendemos que a entrevista se adéqua aos nossos propósitos, porque como admite Moscovici (1978), as conversações veiculam valores, que permitem ao pesquisador se aproximar de objetos simbólicos, como as representações sociais. A entrevista semiestruturada que realizamos com os professores fluiu como uma conversa com os sujeitos.

Os depoimentos das entrevistas foram transcritos, editados e analisados com o auxílio do software Análise Lexical Contextual (ALCESTE). O programa faz uma análise estatística (Classificação Hierárquica Descendente - CHD) de dados, formando classes organizadas por palavras de contexto similar e estáveis, ou seja, com vocabulário semelhante. Essas "classes podem indicar representações sociais ou campos de imagem sobre um dado objeto, ou somente aspectos de uma mesma representação social" (CAMARGO, 2005, p. 517).

O software Alceste foi introduzido no Brasil em 1998, tem sido bastante utilizado em pesquisas que utilizam a Teoria das Representações Sociais e possibilita a geração de classes lexicais formadas por Unidades de Contexto Elementar (UCEs). Elas são organizadas em relatório próprio, disponibilizado pelo programa na forma de dendrograma ${ }^{1}$. O software separa as palavras nas classes com base na semelhança de conteúdo e importância que elas tiveram durante as entrevistas.

11 Dendrograma é um tipo específico de diagrama ou representação icônica, alguns denominam de árvore, que organiza as classes resultantes do processamento estatístico do Alceste. 


\section{RESULTADOS E DISCUSSÃO}

Após o processamento, o software Alceste, através da CHD, gerou o dendrograma (Figura 1), que dividiu o corpus de entrevistas em quatro classes. Elas estão articuladas e foram nomeadas de acordo com o conjunto das palavras e seus contextos de verbalização. Respeitando o conteúdo de cada agrupamento, as classes foram, respectivamente, denominadas de: Classe 1: Perspectivas profissionais; Classe 2: Profissão docente; Classe 3: Desafios do início da carreira; e Classe 4: Formação docente. Com as referidas classes, dispostas na Figura 1, procuramos caracterizar as representações do ser professor construídas por docentes iniciantes que atuam no ensino médio, indicando consensos e variações nas representações do intergrupo.

Figura 1 - Dendrograma referente à Classificação Hierárquica Descendente (CHD) do corpus: entrevistas com docentes iniciantes de ensino médio

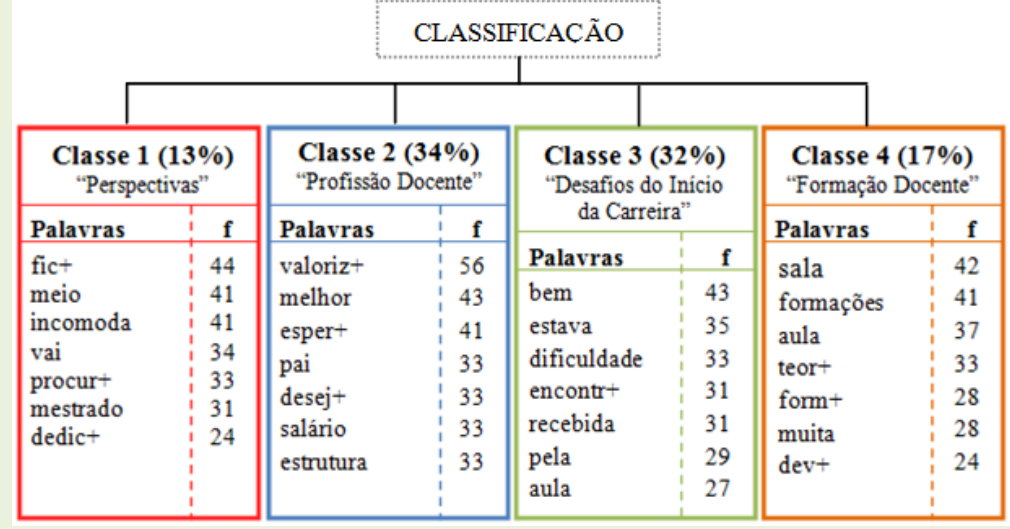

Fonte: software Alceste

\section{Classe 1: Perspectivas Profissionais}

Esta classe, Perspectivas profissionais, concentra $13 \%$ do corpus analisado e aborda as perspectivas profissionais dos entrevistados. Conforme expressaram em suas falas, a maioria dos entrevistados deseja continuar na área da educação, conforme o que se segue: oito professores desejam continuar na docência de ensino médio; cinco professores querem seguir carreira universitária; e dois entrevistados pretendem seguir outra profissão. Os depoimentos sugerem que todos desejam procurar o melhor para si e, 
algumas vezes, isto implica em mudar de profissão ou atuar em nível educacional mais elevado. Afirmam:

Pretendo investir na outra graduação, eu gosto da educação, mas temos que pensar no que é melhor pra gente e agora quero investir em outras coisas (PEM-5) ${ }^{12}$.

O olhar deve ser voltado para o que o professor necessita em sala de aula, porque não é só colocar um professorem escola... Tem que dar estrutura e instrumento de trabalho pra ele, pra ele poder de alguma forma dar uma aula diferente e fazer o aluno se envolver. Não pretendo prosseguir como professora o desse nível, mas quero ir além. Continuar no ensino médio, não (PEM-4).

Os entrevistados que desejam prosseguir na carreira informam que, mesmo com a atual realidade das escolas de ensino médio, da deficiência de material didático, equipamentos, baixo salário, não se veem deenvolvendo outra atividade que não seja lecionar para um público com o qual se identificam e se realizam profissionalmente. Eis alguns trechos ilustrativos das entrevistas:

[...] eu prefiro aluno do ensino médio, porque são maiores e mais maduros pra trabalhar conteúdo. Como não me vejo vivendo de outra coisa, vou seguir até onde a vida permitir. Até a morte! Eu não quero sair da educação, não... Eu ainda acredito mesmo que a atual realidade diga outra coisa, a gente tenta né, mas eu não quero sair, não (PEM-3).

[...] Não me vejo em outra coisa, eu gosto da sala de aula, eu gosto dessa interação. Fazer o quê? Eu faço o que gosto e me dá muita satisfação dividir o conhecimento também (PEM-7).

[...] Sim, pretendo continuar. Porque, apesar de tudo e todas as dificuldades, é onde me realizo profissionalmente (PEM-14).

Os professores que almejam seguir a carreira universitária informam que os motivos para não desejarem continuar como docentes do ensino médio são os seguintes: desvalorização da educação e da profissão de

${ }^{12}$ Codificamos os participantes utilizando a letra PEM (professor de ensino médio) seguida do $n^{\circ}$ de ordem de realização da entrevista. 
professor e dificuldades para lidar com o público de jovens e adolescentes. Sobre o processo de desvalorização docente, Gatti (2014, p. 63) afirma:

\begin{abstract}
A desvalorização profissional é, de fato, uma situação que oprime e desqualifica a força de trabalho, reforça os processos de proletarização do magistério e acentua a concepção de que ser professor é uma atividade de menor valor social. Essa realidade acaba mesmo por reforçar as tensões entre os professores e a sociedade, mais precisamente as tensões entre os docentes e as famílias dos alunos.
\end{abstract}

Nas falas dos entrevistados, identificamos um consenso em torno das perspectivas profissionais, pois desejam continuar docentes, mas reconhecem que o exercício do magistério requer maior valorização no âmbito financeiro, pessoal e profissional. O grupo maior de entrevistados é constituído por professores de Língua Portuguesa, com formação em Letras e, embora compartilhem das mesmas dificuldades e expectativas dos demais entrevistados, trata-se de um subgrupo de professores com depoimentos menos pessimistas do que os demais professores entrevistados. Afirmam:

Espero que a profissão seja mais valorizada, não só financeiramente, mas pessoal também, a sociedade precisa respeitar o professor enquanto ser humano e profissional (PEM11).

Todo professor deseja que seu trabalho seja reconhecido pela sociedade como uma prioridade na vida de cada educando e seja recompensado adequadamente para que não precise trabalhar três turnos para ganhar um salário digno (PEM-13).

Nos depoimentos, detectamos que os docentes iniciantes das demais disciplinas do ensino médio são menos favoráveis à docência e suas perspectivas. Estes professores comentam:

Não pensei que essa profissão fosse tão desvalorizada. Acabou com toda minha esperança. Só não acabou com meu comprometimento e responsabilidade, mas falo do amargor de ser desvalorizado (PEM-12).

Infelizmente, do início da graduação pra agora, muita coisa mudou na minha cabeça, antes eu sonhava muito em sempre 
ser professora [...] principalmente pela questão do reconhecimento (PEM-8).

Assim, podemos afirmar que, na classe 1, os consensos estão relacionados ao desejo de continuar na docência, expectativas de maior reconhecimento e valorização profissional. As variações estão concentradas entre os professores de Química, Física e Geografia, que são mais pessimistas e fazem menção às difíceis condições de trabalho, por exemplo, lidar com o desinteresse e indisciplina dos alunos e falta de reconhecimento social da profissão. Desse modo, os achados reforçam Doise(2002), quando afirma que as repressntações sociais de um grupo possui elementos que são consensuais e outros diversificados.

\section{Classe 2: Profissão Docente}

Esta classe, Profissão docente, organiza os depoimentos relacionados ao que significa ser professor hoje. Constitui a maior das classes da Figura 1 e organiza $34 \%$ do corpus analisado. Ao tratarem sobre a docência, as falas dos professores sugerem um sentimento geral de desvalorização. Os docentes expressam o desejo de que a profissão docente seja mais valorizada, pois são muitos os desafios enfrentados. Em suas falas destacam a desvalorização social, os baixos salários, a precarização da formação e a evasão profissional. Fazem referências ao contexto atual de cortes e restrições à educação, considerados como elementos que tendem a agravar ainda mais o exercício da profissão.

A profissão vai ficar muito escassa, tendo em vista essa PEC, cada vez mais desvalorizada e antigamente você via um numero grande de alunos que queriam ser professor, mas hoje em dia as pessoas não querem mais ser professor (PEM-2).

O professor precisa de maior valorização, mais respeito e principalmente melhores condições de trabalho, nós estamos formando pessoas para o futuro de amanhã (PEM-11).

Todo professor deseja que seu trabalho seja reconhecido pela sociedade como uma prioridade na vida de cada educando e seja recompensado adequadamente para que não precise trabalhar três turnos para ganhar um salário digno (PEM-13). 
Nos depoimentos, são recorrentes as expectativas dos professores iniciantes do ensino médio por melhorias e mudanças na profissão. Um dos entrevistados afirma:

Eu espero que a profissão mude, que haja mudanças tanto em termos de valorização, principalmente a valorização do professor e não é só financeiramente, mas enquanto uma profissão[...] mas eu creio que as coisas podem mudar, né? Depende muito dos gestores, dos políticos, é uma serie de coisas (PEM-1).

A profissão vem sofrendo depreciação e, notadamente, as condições para o seu exercício têm sido alvo de descaso. Como podemos conferir no trecho de fala abaixo, além do salário, os professores se queixam de outros problemas de ordem pedagógica e didática:

[...] a superlotação das turmas, a falta de material para desenvolver um trabalho com excelência, estrutura física, segurança e salários dignos, pois os salários são baixos, principalmente, para os que estão começando (PEM-11).

Algumas das situações relatadas pelos professores estão relacionadas ao que se denomina mal-estar docente. A esse respeito, Timm (2015) afirma que ser professor hoje em dia deixou de ser algo compensador, pois, além dos salários nada atrativos, perdeu-se também o status social que, décadas atrás, acompanhava a profissão. Para o referido autor, a educação básica ainda requer investimentos para atender as demandas crescentes que se apresentam aos professores e que incidem em situações adversas no exercício da profissão. Essa realidade pode levar o docente a situações de mal-estar, tanto na sua vida profissional como na pessoal.

Quando questionados sobre o significado do ser professor, os depoimentos organizados na classe 2 indicam consensos em relação ao docente como muito além de um transmissor de conhecimentos. Os docentes iniciantes de ensino médio partilham representações do ser professor como o profissional capaz de contribuir para a formação de 
"sujeitos transformadores" e ressaltam os desafios da profissão, considerada a mais importante, pois é destinada ao desenvolvimento e construção do cidadão. Afirmou um dos entrevistados:

Para mim, ser professor é uma das profissões mais importantes do mundo, porque a gente, além de formar cidadãos, a gente forma, a gente educa, a gente não é só o elo de ligação do conhecimento. A gente tem que ser um educador (PEM-3).

Os resultados desta classe revelam que as representações do grupo em torno do ser professor estão centradas no ser educador, alguém que contribui para a formação do indivíduo, tendo em vista a transformação social. Os professores compartilham dessas representações, que são construídas no diálogo com o outro e preservam a identidade do grupo.

Na classe 2, não localizamos variações nos depoimentos dos docentes, pois o ser professor é representado como um educador que, além de ensinar e transmitir conhecimentos, procura formar o cidadão, contribuindo para transformar pessoas.

\section{Classe 3: Desafios do Início da Carreira}

Na terceira classe, Desafios do início da carreira, estão concentrados depoimentos relativos aos obstáculos vivenciados pelos docentes iniciantes do ensino médio em suas práticas. Esta classe organiza $32 \%$ do corpus de depoimentos. Dentre os problemas enfrentados pelos participantes da pesquisa, destacamos: falta de recursos pedagógicos e equipamentos, estrutura física falha das escolas, inadequação de material didático, distância entre a teoria e a realidade da sala de aula e exercício de funções variadas. No entanto, alguns dos entrevistados mencionam as estratégias que utilizam para enfrentar os desafios. Afirmam:

Existem vários desafios. Um deles é necessidade hoje de exercer varias funções na escola, outra é conciliar as teorias de aprendizagem com as condições reais da prática, essas pra mim são as grandes dificuldades (PEM-7).

[...] é com relação ao material didático, porque os livros não obedecem muitas vezes ao que é estipulado pela própria 
secretaria de educação, é um choque de conteúdos... (PEM$5)$.

[...] Então meu maior desafio é fazer com que eles tentem aprender e assistir a aula de maneira tranquila e prazerosa pra que eles tentem aprender da melhor forma possível. [...] eu sofro muita represália por isso, não é por parte dos professores, mas por parte dos próprios alunos porque eles... A educação familiar da galera é muito ruim (PEM-3).

Falta de valorização humana; estrutura física e de recursos precárias; política educacional mal aplicada e gerenciada... Vou superando, abstraindo como se nada disso estivesse acontecendo. Procuro me dedicar aos meus alunos. Construo meu próprio material didático utilizando papel, folha adesiva, papelão, cola, papel colorido, etc[...] Ficar pensando no que não temos vai apenas atrasar nossas vidas (PEM-9).

Os entrevistados enfatizaram a preocupação com o domínio dos conteúdos específicos a serem ensinados, elaboração de planejamento, trabalho individual na escola e o baixo nível de aprendizagem dos alunos. Afirmam:

Vamos tentando superar... Uma coisa que eu comento com meus colegas é que temos pouco tempo pra discussões pedagógicas. Como melhorar a prática? $\bigcirc$ que nossos colegas estão fazendo pra melhorar a prática, essa troca de experiência é muito bom (PEM-7).

[...] dificuldade em elaborar aula e fazer planejamento. Isso te toma muito tempo sabe, e como professor você tem várias turmas, ai você acaba levando trabalho pra casa, principalmente professor de língua portuguesa, porque tem que trabalhar gramática, literatura, língua portuguesa, intepretação de texto, então você tem muito trabalho. E quando você leva pra casa, você deixa de viver a sua vida, então ou você se desliga ou você... Então, essa é minha dificuldade maior. Pra superar, "a gente se vira nos 30". A gente faz o que é possível, sempre moldar a aula de acordo com o aluno... (PEM-6).

Outro desafio compartilhado pelos docentes iniciantes de ensino médio diz respeito às suas dificuldades para lidar com os alunos em sala de aula, particularmente, o desinteresse e falta de estímulo dos adolescentes para aprender. Afirmam: 
O desafio é o de tentar fazer com que os alunos se interessem e queiram estudar minha matéria. Encontro uma resistência muito grande por parte deles, mas dou o meu máximo. Estou sempre estudando formas de fazer a aula ficar mais interessante, achando formas de tentar ter a atenção deles. Esse é o desafio que mais enfrento (PEM-11).

[...] é a preguiça dos alunos, muitas vezes é desestimulante você chega na sala de aula e eles estão lá "arriados", a cabeça abaixada, outros no celular, uns compartilhando fone de ouvido, né. É você nadar contra a maré (PEM-2).

Caramba! A primeira talvez seja o pouco interesse dos alunos... Mas, o empenho e a vontade de mudar as coisas me faz pular os obstáculos. Por isso me policio para ter aulas interessantes... Nem que seja uma roda de diálogo (PEM-10).

Olha, meus desafios são os de levar o aluno à motivação individual ao aprendizado, não só na disciplina que leciono, como na de meus colegas (PEM-13).

A falta de interesse, depois é a falta de base em matemática e em português e, por último, é a falta de fé em si mesmos dos alunos (PEM-14).

Como é possível depreender dos depoimentos, os professores iniciantes de ensino médio compartilham inúmeros desafios, porém, talvez a maior dificuldade seja em lidar com o desinteresse e falta de atenção dos alunos. No âmbito da produção científica, outros estudos, como os de Lima (2006), Nono e Mizukami (2006), desenvolvidos com professores iniciantes de ensino fundamental, foram mais discretos no que se refere a este obstáculo, que talvez seja mais comum aos adolescentes matriculados no ensino médio.

No conjunto geral do material discursivo reunido nesta classe, houve uma diminuta variação relativa aos desafios indicados pelos professores. As variações ocorrem nos seguintes aspectos: ausência de trabalho coletivo na escola e discussão entre pares; deficiência dos alunos no processo de aprendizagem anterior ao ingresso no ensino médio; e políticas educacionais pouco efetivas e mal gerenciadas. Identificamos estas variações entre 
professores iniciantes de História e Língua Portuguesa, eis alguns de seus comentários:

[...] temos pouco tempo pra discussões pedagógicas, como melhorar a prática, o que nossos colegas estão fazendo pra melhorar a prática, essa troca de experiência é muito bom (PEM-7).

[...] ter que modificar muitas coisas que foram aprendidas de forma errada antes do ensino médio ou que até nem foram atendidas por falta de professores capacitados e etc. (PEM-8).

[...] Falta de valorização humana e política educacional mal aplicada ou gerenciada (PEM-9).

Os depoimentos revelam que os professores iniciantes de ensino médio vivenciam o choque de realidade. Conforme Huberman (1995) e Mariano (2012), no início da carreira, os docentes enfrentam esse choque, em decorrência das diferenças existentes entre o que é aprendido durante a graduação e o que é encontrado pelo docente na escola e na sala de aula. Tardif (2002) denomina esse sentimento de choque de transição, pois é a passagem do ser estudante para o ser professor. Huberman (1995) apresenta outros dois sentimentos, que tomam conta do professor iniciante: a descoberta e a sobrevivência. A descoberta ocorre quando o iniciante começa a se sentir como professor, pois percebe que tem uma sala de aula; e a sobrevivência se manifesta, por exemplo, na seguinte questão: "o que eu estou fazendo aqui?". Foi possível identificar tais sentimentos no grupo de professores de ensino médio entrevistado. O que diz a professora "antes eu sonhava muito em ser professora, mas hoje em dia vejo que a coisa não é tão fácil assim" (PEM8) é ilustrativo desse conflito inicial.

\section{Classe 4: Formação Docente}

A classe 4, Formação docente, organiza $17 \%$ do corpus e aborda as dificuldades de articulação entre teoria e prática. Basicamente, os entrevistados destacam os limites da formação inicial na preparação do professor para atuar na escola pública. Nos depoimentos, a prática é 
reconhecida como fundamental para a aprendizagem do ser professor. Afirmam:

Acho que a faculdade não ensina a ser professor... Ensina o conteúdo, mas mesmo assim cadeiras práticas não chegam perto da responsabilidade de ensinar, de "dominar" a turma, de evitar criar animosidade com aluno ou turma. Isso só se aprende no erro e acerto, na prática (PEM-14).

A formação acadêmica não te faz ser professor, ela ajuda nos conhecimentos e como orientá-los, mas não é só isso (PEM-15).

A graduação contribuiu, mas poderia contribuir muito mais se o currículo universitário se aproximasse mais da realidade de sala de aula. É uma diferença muito grande o que você estuda da realidade da sala de aula (PEM-11).

Bem, antes de qualquer coisa, o conteúdo foi importante, por outro lado, pelo menos na minha graduação há um distanciamento do que eu vejo na graduação pra aquilo que eu tenho que por em sala de aula, passamos bom tempo estudando teoria. Mas, o exercício, a prática não tem. E quando você vai pra sala de aula você sente, ficamos sem saber o que fazer, mas só com o tempo você consegue transformar a teoria em algo que funcione (PEM-7).

A falta de articulação entre teoria e prática, o distanciamento da formação inicial da prática vivenciada pelo professor na escola são tratados na literatura. Pimenta (1999), por exemplo, considera que a formação é, na verdade, autoformação, uma vez que os professores reelaboram os saberes iniciais, em confronto com suas experiências práticas cotidianamente nos contextos escolares. Mariano (2012) ressalta a necessidade da articulação entre teoria e a prática na formação dos professores, e afirma que as agências formadoras devem viabilizar e colaborar com a formação contínua dos futuros professores, por exemplo, propiciando momentos de reflexão individual e coletiva sobre a prática pedagógica.

Sobre a contribuição da formação para prática docente, identificamos variações nas falas dos participantes, pois sete professores consideram que a formação inicial foi relevante e indispensável, pois se tornou um apoio valioso nos primeiros contatos com a sala de aula. Afirmam, 
ainda, que tal suporte propiciou um maior amadurecimento. Porém, oito docentes declaram que tiveram dificuldade em relacionar teoria e prática em sala de aula, pois se sentiram perdidos e foram aprendendo a lidar com tal deficiência no exercício da profissional. Os docentes licenciados em Letras apresentaram variações, quando se referem à relação teoria e prática na sala de aula. Dos sete entrevistados, quatro docentes informam que a formação inicial ofereceu suporte para a docência e três reconhecem a deficiência da formação acadêmica. Dessa classe 4, podemos depreender que, embora os entrevistados não desprezem os saberes adquiridos na formação, compartilham a representação de que a prática, ou seja, o exercício profissional é o elemento que mais propicia aprendizagem do ser professor.

\section{CONSIDERAÇÕES FINAIS}

Os resultados da pesquisa bibliográfica acerca do professor iniciante são reafirmados e aprofundados pelas constatações tratadas neste artigo, pois os primeiros anos da docência caracterizam-se por sua relevância para a aprendizagem profissional e, consequentemente, para a construção do alicerce da docência. Nesse grupo, há um consenso em relação aos desafios enfrentados no início da carreira, tais como: trabalho individualizado, falta de cooperação dos colegas, inexperiência para lidar com as turmas, desinteresse dos alunos, precarização das escolas e desvalorização do docente.

As representações do ser professor dos docentes de ensino médio ressaltam o papel e importância do serviço prestado pelo professor à sociedade. Os depoimentos dos entrevistados sugerem representações sociais da profissão docente centradas na capacidade de mediação do conhecimento e possibilidade de transformação social. Contudo, tais representações estão marcadas pelo sentimento de desvalorização profissional. Os iniciantes na docência reiteram que diferentes elementos de precarização afetam a profissão hoje, tais como baixo prestígio social da profissão, má remuneração, exigências constantes por parte dos sistemas, 
indisciplina, desinteresse dos alunos e violência escolar.

Os achados da pesquisa são relevantes para a formação de professores e suscitam reflexões acerca da implementação de políticas públicas, que venham a oferecer um maior apoio aos profissionais que estão iniciando a carreira e atuam em instituições públicas de ensino médio.

Além de detectar o cenário de desvalorização do docente de ensino médio e suas influências para as práticas dos professores iniciantes, sugerimos a implementação de políticas públicas, que acolham e ofereçam maior suporte ao professor em início de carreira. Entendemos que políticas e ações mais efetivas que estimulem o exercício e permanência do professor na docência poderão contribuir para fortalecer e qualificar a educação pública.

\section{REFERÊNCIAS}

ALVES, C. S.; ANDRÉ, M. E. D. A constituição da profissionalidade docente: os efeitos do campo de tensão do contexto escolar sobre os professores. In: REUNIÃO NACIONAL DA ANPEd, 36, 2013, Goiânia-GO. Anais [...]. GoiâniaGO, 2013. Disponível em: http//. www.anped.org.br. Acesso em: 28 jul. 2017.

BRASIL, Lei No 9.394/96 de 20 de dezembro 1996. Lei de Diretrizes e Bases da Educação Nacional.

CAMARGO, B. V. ALCESTE: um programa informático de análise quantitativa de dados textuais. In: MOREIRA, A. S. P. (Org.). Perspectivas teóricometodológicas em representações sociais. João Pessoa: UFPB/Ed. Universitária. 2005. p. 511-539.

CERICATO, I. L. A profissão docente em análise no Brasil: uma revisão bibliográfica. Revista Brasileira de estudos pedagógicos, Brasília; v. 97, n. 245. p. 273-289, maio/ago.2016.

CORADINI, L. Reforma do ensino médio: o novo papel da educação pública no Brasil. Jornal Pragmatismo Político. Disponível em: https://www.pragmatismopolitico.com.br/2017/03/reforma-ensino-medioeducacao-publica.html. Acesso em: 07 nov. 2018

CORRÊA, P. M; PORTELLA. V. C. M. As pesquisas sobre professores iniciantes no Brasil: uma revisão. Olhar de professor, Ponta Grossa, v. 15, n. 2, p. 223-236, 2012. 
CUNHA, R. C.; VOLTARELLI, M. A.; COSTA, C. S. Pesquisas sobre o professor iniciante no programa de pós-graduação em educação da UFSCAR: o estado do conhecimento de 2000-2010. Revista Educação e Linguagens, Campo Mourão, v. 2, n. 3, jul./dez. 2013.

DOISE, W. Da psicologia Social a Societal. Psicologia: Teoria e Pesquisa, v.18, n. 1, p. 27-35, 2002.

DOISE, W. Atitudes e representações sociais. In: JODELET, D. (Org). As representações sociais. Rio de Janeiro: EdUERJ, 2001. p. 187-204.

DOURADO, L. F. A reforma do Estado e as políticas de formação de professores nos anos 1990. In: DOURADO, L. F.; PARO, V. H (Orgs.). Políticas públicas \& educação básica. São Paulo: Xamã, 2001.

DUBAR, C. A socialização: construção das identidades sociais e profissionais. São Paulo: Martins Fontes, 2005.

ENGUITA, M. F. La condición del docente. In. La escuela a examen: un análisis sociológico para educadores y otras personas interesadas. Salamanca: Ediciones Pirámide, 1998.

GARCÍA, M. C. Formação de professores para uma mudança educativa. Porto: Porto, 1999.

GATTI, B. O que se percebe é que a questão da docência é sempre relegada como se fosse algo menor. Cadernos Cenpec, São Paulo, v. 4, n.2, p. 248-275, dez. 2014.

HYPOLITO, A. M. Trabalho docente e profissionalização: sonho prometido ou sonho negado? In: VEIGA, I. P. A.; CUNHA, I. M (Orgs.). Desmistificando a profissionalização do magistério. Campinas: Papirus, 1999, p. 81-100.

HUBERMAN, M. O ciclo de vida profissional dos professores. In: NÓVOA, A. (Org.). Vidas de professores. 2. ed. Porto: Porto Ed., 1995. p. 31-61.

KRAWCZYK, N.; FERRETTI C. J. Flexibilizar para quê? Meias verdades da "reforma". Revista retratos da escola, Brasília, v.11, n.20, p.33-44, jan./jun. 2017.

LIMA, E. F. de et al. (Org.). Sobrevivências no início de carreira. Brasília: Líber Livro Editora, 2006.

LÜDKE, M.; BOING, L. A. Globalização e educação: precarização do trabalho docente caminhos da profissão e da profissionalidade docentes. Educação e Sociedade, Campinas, v. 25, n.89, set./dez. 2004. 
MACHADO, J. S. Trilhando pesquisas sobre professores iniciantes: um estudo do estado da arte. Revista Humanidades e Inovação. v.4, n. 2. 2017.

MACHADO, L. B.; RAPOSO, M. M.; CASTRO, T. R. Representações Sociais do bom professor nos ciclos de aprendizagem. Revista de Administração Educacional. Recife, v.1, n.2, jul./dez. 2015.

MARIANO, A. L.S. A aprendizagem da docência no início da carreira: qual política? quais problemas? Revista Exitus, v. 2, n. 1, p. 79-94, Jan./Jun. 2012.

MOSCOVICl, S. A representação social da psicanálise. Tradução de Álvaro Cabral. Rio de Janeiro: Zahar, 1978. 291 p.

NONO, M. A.; MIZUKAMI, M. G. N. Processos de formação de professoras iniciantes. In: REUNIÃO ANUAL DA ANPED, 29, 2006, Caxambu. Anais [...]. Caxambu: ANPED, 2006.

PAPI, S.; MARTINS, P. Professores iniciantes: as pesquisas e suas bases teóricometodológicas. Linhas Críticas, Brasília, v. 14, n. 27, p.251-269, jul./dez. 2009.

PAPI, S. O. G.; CARVALHO, C. B. Professores iniciantes: um panorama das investigações brasileiras. Olhar de professor, Ponta Grossa, v.16, n. 1, p.186202, 2013.

PIMENTA, S. G. Formação de professores: Identidade e saberes da docência. In: PIMENTA, S. G. (Org.). Saberes pedagógicos e atividade docente. São Paulo: Cortez, 1999.

SÁ, C. P. de. A construção do objeto de pesquisa em representações sociais. Rio de Janeiro: EDUERJ, 1998.

TARDIF, M. Saberes docentes e formação profissional. Petrópolis, RJ: Vozes, 2002.

TARDIF, M.; LESSARD, C. O trabalho docente: elementos para uma teoria da docência como profissão de interações humanas. Petrópolis: Vozes, 2005.

TIMM, J. W. O trabalho docente em tempos líquidos: Reflexões sobre o processo saúde-doença. In: SEMINÁRIO BRASILEIRO DE ESTUDOS CULTURAIS E EDUCAÇÃO, 6, 2015, Rio Grande do Sul. Anais [...]. Rio Grande do Sul, 2015.

WEBER, S. Profissionalização docente e políticas públicas no Brasil. Educação e Sociedade. Campinas, v. 24, n. 85, dez, 2003, p. 1125-1154.

Recebido em: 06 de setembro de 2019

Aprovado em: 12 de janeiro de 2020 